\title{
A review of factors influencing litter size in Irish sows
}

Peadar G. Lawlor and P. Brendan Lynch

Teagasc, Pig Production Development Unit, Moorepark Research Centre, Fermoy, Co. Cork

\section{Corresponding author:}

Peadar G. Lawlor, Teagasc, Pig Production Development Unit, Moorepark Research Centre, Fermoy, Co. Cork

Email: peadar.lawlor@teagasc.ie

Tel: +3532542217 Fax: +3532542340

\begin{abstract}
Many factors influence litter size. These include genetics, gilt management, lactation length, parity distribution, disease, stress and boar fertility. In the past 20 years, litter size in Irish sows has increased by only one pig. Born alive figures now average at 11.2 pigs per litter. In this regard, Ireland is falling behind our European competitors who have made significant advances over this time. Denmark, for example, has an average figure of 12.7 pigs born alive per litter and France an average of 12.5. The single area that could be improved immediately is sow feeding. It is important that sows are fed correctly throughout pregnancy. If over-fed during pregnancy, sows will have depressed appetite during lactation. If underfed in pregnancy, sows will be too thin at farrowing. The correct way to feed a pregnant sow is to match her feed allocation to her requirement for maintenance, body growth and growth of her developing foetuses. During lactation, sows should be given as much feed as they can eat to prevent excessive loss of body condition. Liquid-feed curves should be such that lactating sows are provided with a minimum mean daily feed supply of $6.2 \mathrm{~kg}$. A small proportion of sows will eat more and this could be given as supplementary dry feed. Where dry feeding is practised in the farrowing house, it is difficult to hand-feed sows to match their appetite. Ideally ad libitum wet/dry feeders should be used. From weaning to service, sows should once again be fed ad libitum. If liquid feeding, this means giving at least 60MJ DE (digestible energy) per day during this period. If dry feeding, at least $4 \mathrm{~kg}$ of lactation diet should be fed daily. The effort spent perfecting sow feeding management on units should yield high dividends in the form of increased pigs born alive per litter.
\end{abstract}

Key words: litter, size, Ireland, sows

Irish Veterinary Journal Volume 60 Number 6, 359-366, 2007

\section{Introduction}

In the past 20 years, litter size in Irish sows has increased by almost one pig. However, most of this increase had occurred by 1996. Since then, litter size has increased by only 0.40 of a pig (Table 1 ). When broken down into quartiles, the 2005 PIGSYS data show that there is a difference of 1.1 pigs in number born alive and in total born between the top 25\% and bottom 25\% performing herds (Table 2). However, even the top quartile is falling behind our European competitors (Table 3). Denmark, for example, had an average born alive figure of 12.7 in 2004 compared to the 11.6 figure for the top $25 \%$ of Irish herds in 2005 .

Table 1: Trend in litter size from sows in Ireland over last 20 years (PIGSYS report 2006)

\begin{tabular}{|l|l|l|l|}
\hline Year & No. born alive & No. born dead & Total born \\
\hline 1986 & 10.3 & 0.63 & 11.0 \\
\hline 1996 & 10.8 & 0.74 & 11.6 \\
\hline 1997 & 10.9 & 0.76 & 11.6 \\
\hline 1998 & 10.8 & 0.74 & 11.6 \\
\hline 1999 & 10.9 & 0.76 & 11.7 \\
\hline 2000 & 10.9 & 0.76 & 11.6 \\
\hline 2001 & 10.8 & 0.75 & 11.5 \\
\hline 2002 & 11.0 & 0.76 & 11.7 \\
\hline 2003 & 11.0 & 0.78 & 11.8 \\
\hline 2004 & 11.2 & 0.74 & 11.9 \\
\hline 2005 & 11.2 & 0.74 & 11.9 \\
\hline
\end{tabular}

This paper will attempt to address some of the factors that are limiting litter size in Ireland. Genetics is obviously an important factor in this regard (but will be discussed only briefly here). However, genetic improvements are worthless unless we possess the management and nutritional information to exploit these advances. Therefore, this paper will concentrate on some of the management and nutrition factors that can make the most improvements in litter size.

Table 2: Litter size in Irish sows based on number born alive (PIGSYS data, 2005)

\begin{tabular}{|l|l|l|l|}
\hline & Top 25\% & Mean & Bottom 25\% \\
\hline Number born alive & 11.6 & 11.2 & 10.5 \\
\hline Number born dead & 0.73 & 0.74 & 0.79 \\
\hline Total born & 12.4 & 11.9 & 11.3
\end{tabular}

Table 3: Number of pigs born alive in select EU countries in 2004(BPEX data, 2005)

\begin{tabular}{|l|l|}
\hline Country & Number born alive \\
\hline Denmark & 12.7 \\
\hline France & 12.5 \\
\hline Sweden & 12.1 \\
\hline Netherlands & 11.9 \\
\hline Ireland* & 11.2 \\
\hline
\end{tabular}

\section{Genetics}

As a result of heterosis, litter size of crossbred sows is on average 0.25 to 0.5 pigs greater than that of purebred sows (Aherne, 2002). Literature estimates of heritability 
of litter size range between 0 and 0.76 with an average of 0.10 (Rothschild and Bidanel, 1998). A policy of selecting gilts from prolific sows, and serving them with boars from a prolific dam line, will gradually increase litter size over time because litter size and its component traits (ovulation rate, embryonic survival and uterine capacity) respond to selection (Johnson et al., 1999). However, it has been suggested that genetic improvement programmes should emphasise live born pigs and weight of live born pigs because of undesirable genetic relationships between ovulation rate and number of foetuses with numbers of stillborn and mummified pigs and because birth weight has decreased as litter size has increased (Johnson et al., 1999).

One of the most important determinants of litter size is failure of the developing foetus to survive (Spötter and Distl, 2006). This occurs most frequently in the first few weeks of gestation and is associated with abnormalities in the developmental process. Improvement in litter size in the past was achieved by phenotypic selection. However, it is now possible to use marker assisted selection (MAP) which utilises genotypic information. Use of this technology will greatly shorten the generation interval as the selection decision can take place early in the life of the animal (Spötter and Distl, 2006).

Selection for increased uterine capacity and, in particular, selection for reduced placental size and increased placental efficiency may also lead to increases in litter size (Ford et al., 2002; Wu et al., 2006)

\section{Gilt selection and management}

There are more gilts served and farrowed than sows of any other parity. Therefore, if gilt litter size is low, the average born alive for the herd will be reduced. In addition, maximising the litter size in gilts will maximise lifetime performance (Dewey et al., 1995; Aherne, 2002). For this reason, it is important that gilt selection and management be carried out correctly.

A retrospective examination of the records from more than 20,000 farrowings on the data bank of a Swedish breeding organisation found that:

- An increase of one piglet in the litter in which a gilt is born results in an increase of her own litter size (both total born and born alive) of between 0.07 and 0.1 piglets (Tummaruk et al., 2001).

- An increase in growth rate from birth to $100 \mathrm{~kg}$ body weight of $100 \mathrm{~g} /$ day results in an increase in litter size (both total born and born alive) of between 0.3 and 0.4 piglets, as well as a reduction in weaning to oestrus interval and an increase in farrowing rate (Tummaruk et al., 2001).

- Gilts with a high backfat at $100 \mathrm{~kg}$ have increased litter size in parity two as well as a shorter weaning to oestrus interval and a higher farrowing rate (Tummaruk et al., 2001).

- As age at first mating increases, so too does litter size
(Dewey et al., 1995; Tummaruk et al., 2001). However, there is a critical age above which litter size will not be increased. When this critical age is reached, litter size will be determined by the number of oestrus cycles that the gilt has reached (Dewey et al., 1995).

The essentials of gilt management and nutrition have been reviewed previously by Carroll and Lawlor (1996) and Young (2003).

\section{Sow feeding}

Feed quality

Certain mycotoxins such as zearalenone, if ingested in early pregnancy, can result in increased embryo mortality and therefore in reduced litter size (Aherne, 2002). It is advisable that sow feed and feed storage areas are kept clean, fresh and free of moulds.

\section{Gestation}

Moderate energy intake (31 MJ DE/day) compared to low energy intake (18 MJ DE/day), in the first three days after mating, may reduce litter size in gilts but not in sows (Kongsted, 2005). Tokach et al. (1999) recommended limiting sow feed intake (28 MJ DE/day) in the first 12 days after service as a safety measure to prevent embryo mortality in the early stage of pregnancy. However, very thin sows should receive a high level of intake immediately after mating until body condition is restored (Tokach et al., 1999).

Litter size may actually be reduced by feeding a very low energy level in the first four weeks of pregnancy (Kongsted, 2005), especially where sows are in a very poor body condition (Tokach et al., 1999). Where sow body condition is poor, additional feed should be provided between day 12 and day 45 of gestation. Sows should be at the body condition desired for farrowing by day 45 of gestation.

Day 75 to day 100 of gestation is the critical period for mammary development and Tokach et al. (1999) recommend that excess feed intake be avoided particularly during this period. However, in practice, feed intake should be such that it only meets requirements for maintenance and conceptus growth at this time as sow body condition should have been restored by day 45 of gestation.

The period from day 100 to day 112 of gestation is also critical in that this is a period wherein rapid foetal growth takes place. Feed intake should be increased by $1-2 \mathrm{~kg}$ during this period to prevent sows from losing weight. Failure to increase feed intake during this period results in sows entering a catabolic state at farrowing. This catabolic state contributes to gorging and sows "going off feed" during lactation (Tokach et al., 1999).

From day 112 to farrowing it is recommended to feed $2 \mathrm{~kg}$ per day (Tokach et al., 1999). See Appendix 1 for recommended gestation feed curves for sows and gilts. 


\section{Lactation}

Improvements in genetics have resulted in sows with higher milk production and maintenance requirements. However, body fat reserves have decreased and voluntary feed intake may have decreased at the same time. As a consequence, voluntary feed intake of sows during lactation is frequently insufficient to meet nutrient demands (Eissen et al., 2000).

Increasing feed intake of lactating sows reduces backfat and body-weight losses as well as increasing litter weight gain (Eissen et al., 2003). Minimising weight loss during lactation is critical when attempting to achieve an early return to oestrus after weaning (Tantasuparuk et al., 2001; Eissen $e t$ al., 2003; Thaker and Bilkei, 2005) and a high litter size at the subsequent farrowing (Eissen et al., 2003; Thaker and Bilkei, 2005). In the study by Thaker and Bilkei (2005), it is evident that weight loss during lactation should not be greater than $5 \%$ (approx. $9 \mathrm{~kg}$ ) for first parity sows and $10 \%$ (approx. 22kg) for older parities, if early return to oestrus, high farrowing rate and a high subsequent litter size are to be achieved. Low parity sows are most affected by lactation weight loss because of their inherent drive to achieve their target lean body mass and therefore, even after weaning, they continue to mobilise body fat to sustain lean tissue deposition (Foxcroft et al., 1997). This leads to an unfavourable endocrine and metabolic state in these young sows which impacts negatively on their fertility. Subsequent ovulation rate is reduced by lactation weight loss (Zak et al. 1997).

In the sow, only extremes of either under or over-nutrition have been reported to influence milk yield (NRC, 1998). The number of piglets suckling the sow has the greatest positive influence on total production of milk (Hartmann $e t$ al., 1997). For this reason, sows on a low level of nutrition will mobilise body reserves for milk production thus losing weight. The extent of weight loss will depend on the energy deficit between requirements for maintenance and for milk production (the number of piglets sucking the sow and their growth rate will determine this) compared with that provided by the feed (NRC, 1998).

According to Koketsu and Dial (1998), greater energy and feed intake during lactation is associated with higher embryo survival rates during the subsequent early gestation period and greater litter size at the subsequent farrowing. This study also demonstrates that increasing feed intake during lactation can reduce the negative association between short lactation length and subsequent litter size.

\section{Computerised liquid feeding}

At Moorepark Research Centre, the authors are currently looking at ways to increase feed intake during lactation in order to minimise weight loss. Appendix 2 shows three feed curves that have been looked at. Curve 1 is the baseline curve, curve 2 is curve 1 plus $15 \%$ and curve 3 is curve 2 plus $15 \%$. The suitability of the three curves is examined in Table 4. Curve 1 provides, on average, 74.3MJ DE/ day $(5.2 \mathrm{~kg} ; 14.2 \mathrm{MJ} / \mathrm{kg} \mathrm{DE}$ diet) and is easily consumed but results in a lactation weight loss of between 23 and $33 \mathrm{~kg}$ (depending on sow weight; Table 4) over a 26-day lactation. Curve 2 provides, on average, $85.5 \mathrm{MJ} \mathrm{DE} /$ day (6kg; $14.2 \mathrm{MJ} / \mathrm{kg}$ DE diet), leads to very little feed rejection and results in lactation weight losses of between 8.4 and $18.1 \mathrm{~kg}$ (depending on sow weight; Table 4) over a lactation of the same duration. Curve 3 provides, on average, $98.3 \mathrm{MJ}$ $\mathrm{DE} /$ day $(6.9 \mathrm{~kg} ; 14.2 \mathrm{MJ} / \mathrm{kg} \mathrm{DE}$ diet) and if consumed in its entirety would actually put weight on most sows over a 26-day lactation (Table 4). However, approximately 50\% of sows cannot consume their full allocation of feed on this curve and valves need to be 'minused' (i.e., their feed levels temporarily restricted) on a regular basis.

It is suggested that curves similar to either curve 2 or 3 be used. If curve 2 is adopted, then it should be fed as two splits (morning and evening) and personnel should be prepared to provide supplementary dry feed at midday to

Table 4: Energy requirement of sows during lactation and sow weight loss during lactation (kg over 26 days) associated with three different lactation feed curves (see Appendix 2).

\begin{tabular}{|c|c|c|c|c|c|c|c|c|c|c|}
\hline & \multicolumn{4}{|c|}{ Energy requirement during lactation } & \multicolumn{2}{|l|}{ Curve 1} & \multicolumn{2}{|l|}{ Curve 2} & \multicolumn{2}{|l|}{ Curve 3} \\
\hline $\begin{array}{l}\text { Sow weight } \\
\text { (kg) }\end{array}$ & $\begin{array}{l}\text { Maintenance } \\
(\mathrm{MJ} D E)^{1}\end{array}$ & $\begin{array}{l}\text { Milk } \\
(\text { MJ DE })^{2}\end{array}$ & $\begin{array}{l}\text { Total } \\
\text { /day (MJ) }\end{array}$ & $\begin{array}{l}\text { Total } \\
\text { /day (kg) }\end{array}$ & Fed (MJ) & $\begin{array}{l}\text { Weight } \\
\text { loss }^{3} \text { (kg) }\end{array}$ & Fed (MJ) & $\begin{array}{l}\text { Weight } \\
\operatorname{loss}^{3}(\mathrm{~kg})\end{array}$ & Fed (MJ) & $\begin{array}{l}\text { Weight } \\
\operatorname{loss}^{3}(\mathrm{~kg})\end{array}$ \\
\hline 180 & 22.6 & 69.0 & 91.6 & 6.45 & 74.3 & 23.4 & 85.5 & 8.4 & 98.3 & -9.1 \\
\hline 190 & 23.6 & 69.0 & 92.6 & 6.52 & 74.3 & 24.7 & 85.5 & 9.6 & 98.3 & -7.8 \\
\hline 200 & 24.5 & 69.0 & 93.5 & 6.58 & 74.3 & 26.0 & 85.5 & 10.9 & 98.3 & -6.5 \\
\hline 210 & 25.4 & 69.0 & 94.4 & 6.65 & 74.3 & 27.2 & 85.5 & 12.1 & 98.3 & -5.3 \\
\hline 220 & 26.3 & 69.0 & 95.3 & 6.71 & 74.3 & 28.4 & 85.5 & 13.3 & 98.3 & -4.1 \\
\hline 230 & 27.2 & 69.0 & 96.2 & 6.77 & 74.3 & 29.6 & 85.5 & 14.5 & 98.3 & -2.9 \\
\hline 240 & 28.1 & 69.0 & 97.1 & 6.84 & 74.3 & 30.8 & 85.5 & 15.7 & 98.3 & -1.7 \\
\hline 250 & 28.9 & 69.0 & 97.9 & 6.90 & 74.3 & 32.0 & 85.5 & 16.9 & 98.3 & -0.5 \\
\hline 260 & 29.8 & 69.0 & 98.8 & 6.96 & 74.3 & 33.2 & 85.5 & 18.1 & 98.3 & 0.7 \\
\hline
\end{tabular}

1 DE for maintenance $(M J D E /$ day $)=\left(\left(110 \times B W^{0.75}\right) / 1000\right) \times 4.1853($ NRC, 1998) where $B W$ is body weight.

2 DE for milk $(M J D E /$ day $)=((((6.83 \times$ ADG x pigs $)-(125 \times$ pigs $)) \times 4.1853) / 1000) / 0.96)(N R C, 1998)$ where ADG is the daily gain of sucking pigs (assumed here as $250 \mathrm{~g} /$ day $)$ and pigs is the number of piglets sucking per sow (assumed here as 10$)$.

3 (Total energy requirement during lactation - Energy fed $) /((5 \times 4.1853 \times 0.88) / 0.96)=$ weight loss (Noblet et al., 1990). 
sows that will consume more. If curve 3 is used, it should be fed as three splits (morning, midday and evening), personnel should be prepared to monitor troughs (one hour after each feed) and when significant quantities of feed are left, individual valves should be 'minused'.

If it is rarely necessary to 'minus' a valve for a particular feed curve then it is reasonable to assume that the curve is too low and that the majority of sows are not getting sufficient feed. The voluntary food intake of individual sows differs greatly and is influenced by a number of factors including ambient temperature, genotype, parity, sow health, lactation stage and litter size (O'Grady et al., 1985; Farmer et al., 2001) and it is the responsibility of the stockperson to ensure that these very individual feed requirements are satisfied. This will involve some additional work but the return to labour in this area will be very worthwhile with improvements resulting in subsequent weaning to service interval, farrowing rate and litter size coupled with increased litter weight at weaning. Another very obvious, though often overlooked, consideration where liquid feeding is carried out, is the trough capacity. The trough must be capable of taking the high levels of feed and water that the sow will require by the second week of lactation. A typical water to feed ratio for lactating sows is $4.1 \mathrm{~kg}$ water: $1 \mathrm{~kg}$ feed DM or $3.6 \mathrm{~kg}$ water: $1 \mathrm{~kg}$ fresh weight feed. At maximum feed (curve 3; Appendix 2) $9.8 \mathrm{~kg}$ fresh weight of feed would be fed per day. Feeding three splits per day would require a trough capacity of 19 litres (15 litres plus 25\%). Feeding two splits per day would necessitate fitting a trough with a minimum capacity of 28 litres (22.5 litres plus 25\%). The additional 25\% capacity is recommended to prevent overflows when sows are feeding.

\section{Dry feeding}

Where sows are hand-fed dry feed in the farrowing house, it is extremely difficult to match the sow's ad libitum feed requirement. Peterson et al. (2004) found a $7 \%$ improvement in feed intake when lactating sows were given ad libitum access to dry feed using a self-feeder. In addition, lactating sows provided with wet feed tend to eat more feed compared with sows given dry feed. O'Grady and Lynch (1978), Koketsu (1994) and Lynch (2001) found the intake of lactating sows to increase by $12 \%, 11 \%$ and $7 \%$, respectively, when feed was fed wet.

A recent study by Peng et al. (2006) compared an ad libitum wet/dry feeder to hand-feeding. Feed intake for the two systems were similar up to day 14 of lactation after which the ad libitum wet-dry fed sows had a $9 \%$ increase in intake. In this study ad libitum wet/dry-fed sows gained more than $6 \mathrm{~kg}$ body weight over a 21-day lactation. Piglet weight at weaning was increased and variation in individual pig weight within litters was reduced. Wastage of water was also reduced on the ad libitum wet/dry feeding treatment as nipple drinkers were incorporated in the trough and not external to it, as was the case where sows were hand-fed.

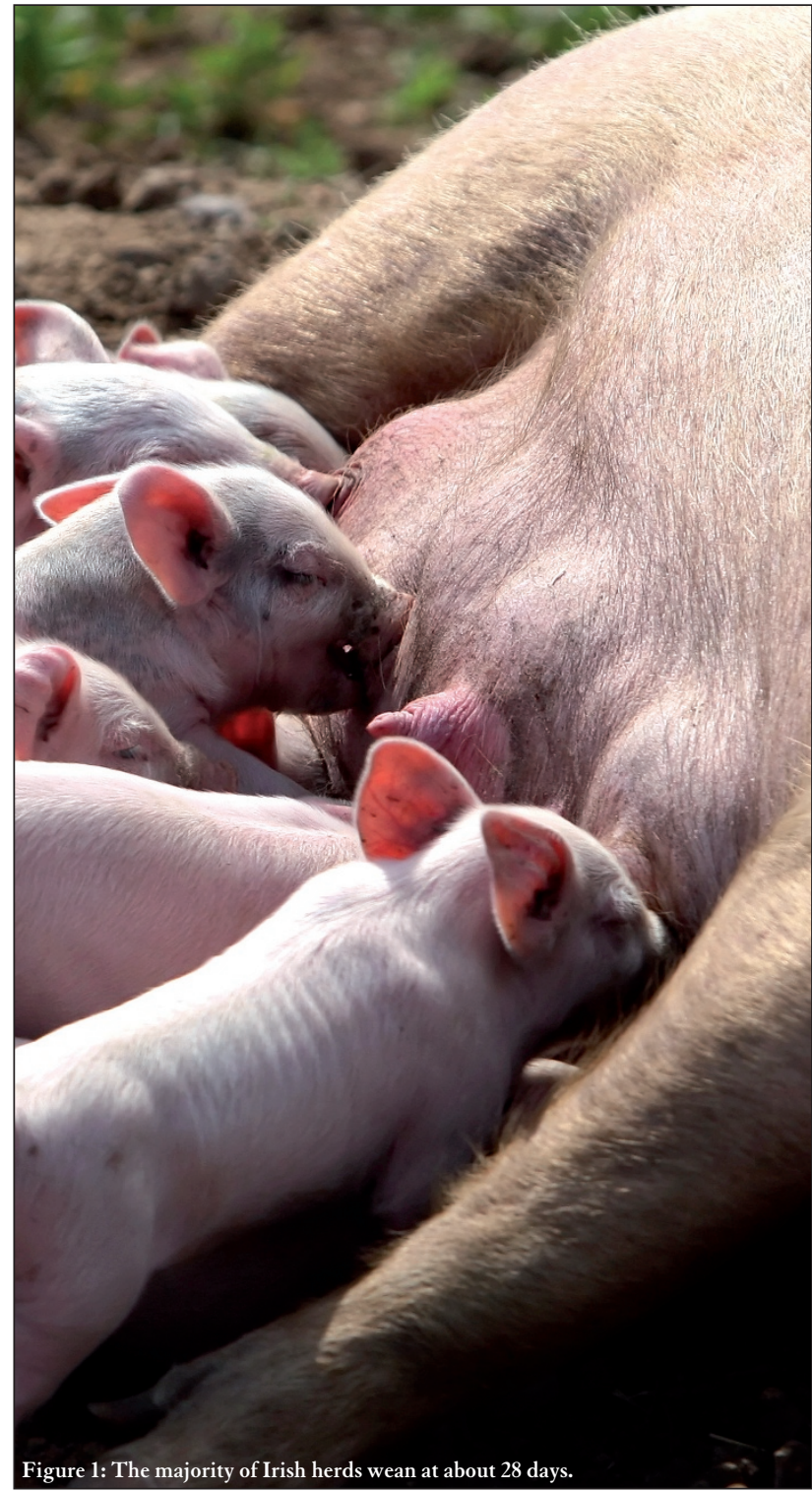

Therefore, it is recommended that where meal or pelleted dry feed is fed to lactating sows ad libitum, wet/dry feeders should be used.

\section{Weaning to service}

Tummaruk et al. (2000) found that subsequent litter size decreased by about one pig when weaning to service interval increased from four to 10 days. This is another reason why feed intake during lactation should be maximised as weaning to service interval is likely to be shorter for sows that have lost least body weight during lactation.

Low energy intake compared to high energy intake before mating may reduce litter size in gilts and sows that experienced severe weight loss during lactation (Kongsted, 2005). For this reason it is recommended that sows should be fed ad libitum after weaning.

\section{Lactation length/weaning age}

The majority of Irish herds wean at about 28 days (Figure 1). The endometrium in the uterus is regenerated between 
14 and 21 days after farrowing. This process, called involution, may not be complete in sows weaned at 21 days or less (especially with older sows). For this reason, sows weaned at 21 days or less are likely to have a reduction in litter size at the subsequent farrowing (Koketsu and Dial, 1998). Each day increase in the farrowing to conception interval (less than 36 days) is responsible for a subsequent increase in number born alive of up to 0.09 pigs (Clark and Leman, 1987).

\section{Parity distribution}

The annual sow replacement rate in Ireland is 52.2\% (46.2\% culling rate and $6 \%$ mortality; PIGSYS, 2005). Based on an average 2.28 litters per sow per year (PIGSYS, 2005), 22.9\% of litters born have to be from gilts in order to maintain sow herd size. Carroll (1999) proposed an ideal parity distribution and, according to his data, gilt farrowings should only account for $17 \%$ of farrowings (Table 5).

Table 5: Ideal parity distribution (Carroll, 1999)

\begin{tabular}{|l|r|r|r|r|r|r|r|r|}
\hline Parity & 1 & 2 & 3 & 4 & 5 & 6 & 7 & $8+$ \\
\hline$\%$ & 17 & 16 & 15 & 14 & 13 & 11 & 10 & $<4$ \\
\hline
\end{tabular}

It is evident that a large number of young sows are culled from Irish herds. To combat this deficiency, it is suggested that strict selection procedures (conformation and structural soundness, feet and leg soundness, reproductive soundness) for gilts on entry to the herd are adopted (Stalder et al., 2004; Lawlor, 2005; Stalder and Bass, 2005a; Stalder and Bass, 2005b).

Litter size usually increases from first to second litter and again from second to third litter, but then plateaus until approximately the seventh or eight litter (Hughes and Varley, 1980; Hughes, 1998). For this reason, it is essential when attempting to achieve a high herd litter size that a high proportion of older sows remain in the herd. To achieve this goal, culling rates must be optimised and it is especially important to avoid situations where excessive numbers of young sows are culled.

Again, using PIGSYS (2005) figures and to achieve the ideal parity distribution in Table 5, the ideal replacement on Irish herds would be $38.8 \%$. It is also important that a high proportion of this culling be voluntary (i.e., based on age and reproductive performance). Rodriguez-Zas et al. (2006) found that reducing involuntary culling at early parities results in increased profitability. It is advisable that sows are culled after parity seven since number born dead tends to increase with older parities and number born alive tends to decline. Allied to this is the reduction in milking ability as the sow ages.

\section{Diseases}

Clinical parvovirus is recognised when a herd suffers an outbreak of SMEDI (stillbirth, mummification, embryonic death and infertility). The clinical signs include a low total number born and a high number born dead/mummified leaving a very low number born alive. However, sows infected with parvovirus in early pregnancy can cause a reduction in litter size without the presence of mummies. A comprehensive parvovirus vaccination programme is recommended and generally adhered to in Ireland though not elsewhere where there are large numbers of sows kept outdoors and where only gilts may be vaccinated. Gilts and sows should be vaccinated three weeks before service. Leptospirosis, PRRS (porcine reproductive and respiratory syndrome) and, occasionally, enterovirus may also reduce litter size (Aherne, 2002).

\section{Movement/stress}

Sows should be moved from the service area to their gestation quarters either within the first 72 hours postbreeding or else at least 28 days after breeding. The stress of moving or mixing before implantation of the embryos has occurred, can result in lower farrowing rates and lower litter size (Aherne, 2002).

\section{Boar fertility}

If boars are either over- or under-worked, a reduction in litter size is likely (Ashenhurst, 1983; Table 6). Ideally, each boar should be used for one double service per week. A boar chart should be used to monitor usage. These records will also be useful in detecting differences among boars. Artificial insemination accounts for as much as $80 \%$ of total services on a high proportion of the large sow herds in Ireland. This means that fewer boars are now kept on these units. However, there will always be a need for some boars (boar power) in these herds for oestrus stimulation and detection and perhaps for gilt matings (Hughes et al., 1990). The recommended maximum sow to boar ratio is 20:1, 50:1 and 67:1 where natural mating accounts for $100 \%$ of services, where $\mathrm{AI}$ is practised on a 100 -sow unit and where $\mathrm{AI}$ is practised on a 1000-sow unit, respectively (Lawlor, 1998).

Table 6: Effect of resting boars on litter size (Ashenhurst, 1983)
\begin{tabular}{|l|l|l|}
\hline Rest period prior to mating (days) & Number of litters & Litter size \\
\hline 0 & 289 & 9.5 \\
\hline $1-2$ & 455 & 10.1 \\
\hline $3-4$ & 253 & 10.1 \\
\hline $5-6$ & 241 & 10.5 \\
\hline $7-9$ & 167 & 10.4 \\
\hline $10-30$ & 200 & 9.6 \\
\hline$>30$ & 36 & 9.8 \\
\hline
\end{tabular}

\section{Timing of service}

Timing of mating/AI is very important (Hunter, 1983). Sows generally ovulate sometime during the last half of their oestrus period and it is critical that sperm are in the reproductive tract before ovulation occurs. If fertilisation does not occur within four hours of ovulation, a sharp reduction in litter size will result (Hunter, 1983; Table 7). Sperm must have time to capacitate or mature in the tract and must be present at the site of fertilisation at or very shortly after ovulation. Sows should be served when first 
detected on heat and again 24 hours later as sperm is likely to survive for 24 hours in the sow's reproductive tract.

Table 7: Effect of age of eggs at fertilisation on the number of viable embryos (Hunter, 1983)

\begin{tabular}{|l|l|l|}
\hline $\begin{array}{l}\text { Age of eggs at } \\
\text { fertilisation (hours) }\end{array}$ & $\begin{array}{l}\text { Percentage of eggs } \\
\text { normally fertilised }\end{array}$ & $\begin{array}{l}\text { Number of viable } \\
\text { embryos at day 25 }\end{array}$ \\
\hline 0 & 90.8 & 12.0 \\
\hline 4 & 92.1 & 11.7 \\
\hline 8 & 94.6 & 8.7 \\
\hline 12 & 70.3 & 6.8 \\
\hline 16 & 48.3 & 4.8 \\
\hline 20 & 50.9 & 5.0 \\
\hline
\end{tabular}

Work at North Carolina State University has shown that when sows exhibit a strong standing heat reflex, have a tight cervical lock on the catheter, and where very little semen flow-back occurs, that a higher conception rate will occur (Steverink et al., 1998; 'Simultaneously optimizing farrowing rate and litter size', 2000).

\section{Other considerations}

- Monitor litter size from natural service and AI. If AI has poorer litter size than natural service, there is likely to be a problem with timing and/or technique and this area should be revised.

- Semen for AI is normally purchased onto Irish units. Ensure that it is handled and stored appropriately to maintain quality (semen should be stored at $17^{\circ} \mathrm{C}$ in a climate box and rotated every 12 hours to prevent separation of the sperm from the diluent).

- Provide adequate and effective lighting in the service area and dry sow house for 12 to 16 hours per day

- Maintain temperature in the dry sow house at $18-20^{\circ} \mathrm{C}$. Each degree Celsius below this will require an additional $1 \mathrm{MJ}$ DE per day to maintain body temperature (NRC, 1998).

- Maintain temperature in the farrowing house as low as possible (provide supplementary heat for piglets by way of a warm creep area or heat pads). This will encourage sow appetite.

\section{Summary}

The average litter size on Irish sow herds is 1.5 pigs less than that of the average for the Danish national herd. This paper has discussed the factors limiting litter size in Ireland, including; genetics, gilt selection and management, sow feeding, lactation length, parity distribution, diseases, movement/stress, boar fertility, timing of service and other considerations. Sow feeding has been identified as the factor where the most immediate improvements could be made. It is important that pregnant sows are fed to closely match their requirement for maintenance, growth and growth of the developing foetus. During lactation, sows should be given as much feed as they can eat to prevent excessive loss of body condition. Where liquid-feeding is practised, this is best achieved by providing a minimum mean daily feed supply of $6.2 \mathrm{~kg}$ of lactation diet on the liquid feed curve and giving supplementary dry feed where sows will eat more. Where dry feeding is practised in the farrowing house, installing ad libitum wet dry feeders to promote intake is advised. From weaning to service, sows should also be provided with ad libitum feed access. The time and effort spent perfecting sow feeding management is likely to be highly cost effective.

\section{References}

Aherne, F. (2002). Improving breeding herd efficiency: an industry perspective. In: Proceedings of the $29^{\text {th }}$ Annual Symposium of the Pig Health Society. Pig Health Society, Dublin. pp30-44.

Ashenhurst, A.L. (1983). Boar Management. In: Proceedings of the $11^{\text {th }}$ Annual Winter Symposium of The Pig Health Society: Efficient Production of Quality Pigmeat. Pig Health Society, Dublin. pp27-36.

BPEX (2005). 2004 pig cost of production in selected EU countries. BPEX: Milton Keynes.

Carroll, C. (1999). Sow culling and parity profiles. In: Proceedings of

Teagasc Pig Farmers Conferences. Teagasc, Sandymount Avenue, Dublin 4. pp35-41.

Carroll, C. and Lawlor, P. (1996). Gilt management 90kg to mating. In: Proceedings of Teagasc Pig Farmers Conferences, Teagasc, Sandymount Avenue, Dublin 4. pp26-33.

Clark, L.K. and Leman, A.D. (1987). Factors that influence litter size in swine: parity 3 through 7 females. Journal of the American Veterinary Medicine Association. 191: 49-58.

Dewey, C.E., Martin, S.W., Friendship, R.M., Kennedy, B.W. and Wilson, M.R. (1995). Associations between litter size and specific sow level management factors in Ontario swine. Preventive Veterinary Medicine 23: 101-110.

Eissen, J.J., Kanis, E. and Kemp, B. (2000). Sow factors affecting voluntary feed intake during lactation. Livestock Production Science 64: 147-165.

Eissen, J.J., Apeldoorn, E.J., Kanis, E., Verstegan, M.W.A. and de Greef, K.H. (2003). The importance of a high feed intake during lactation of primiparous sows nursing large litters. Journal of Animal Science 81: 594603.

Farmer, C., Palin, M.F., Sorensen, M.T. and Robert, S. (2001). Lactational performance, nursing and maternal behaviour of Upton-Meishan and Large white sows. Canadian Journal of Animal Science 81: 487-493. Ford, S.P., Vonnahme, K.A. and Wilson, M.E. (2002). Uterine capacity in the pig reflects a combination of uterine environment and conceptus genotype effects. Journal of Animal Science $\mathbf{8 0}$ (Electronic Supplement 1): pp66-73.

Foxcroft, G.H., Zak, L., Aherne, F.X. and Kirkwood, R.N. (1997). Management of the early weaned sow. In: Proceedings of the Banff Pork Seminar, Advances in Pork Production. Banff, Canada. 8: 117-135.

Hartmann, P.E., Smith, N.A., Thompson, M.J., Wakeford, C.M. and Arthur, P.G. (1997). The lactation cycle in the sow: physiological and management contradictions. Livestock Production Science 50:75-87. Hughes, P.E, Pearse, G.P and Paterson, A.M. (1990). Mechanisms mediating the stimulatory effects of the boar on gilt reproduction: Control of pig reproduction. Journal of Reproduction and Fertility, Supplement 40: 323-341.

Hughes, P.E. (1998). Effects of parity, season and boar contact on the reproductive performance of weaned sows. Livestock Production Science 54: 151-157.

Hughes, P.E. and Varley, M.A. (1980). Reproduction in the pig. Butterworth and Co. Ltd., London. pp241.

Hunter, R.H.F. (1983). Physiological components of fertility in domestic 
pigs. In: Proceedings of the $11^{\text {th }}$ Annual Winter Symposium of The Pig Health Society: Efficient Production of Quality Pigmeat. Pig Health Society, Dublin. pp15-26.

Johnson, R.K., Nielsen, M.K. and Casey, D.S. (1999). Responses in ovulation rate, embryo survival and litter traits in swine to 14 generations of selection to increase litter size. Journal of Animal Science 77: 541-557.

Koketsu, Y. (1994). Influence of feed intake and other factors on the lactational and postweaning reproductive performance of sows. $\mathrm{PhD}$ Dissertation.

University of Minnesota, St. Paul, Minnesota, USA.

Koketsu, Y. and Dial, G.D. (1998). Interactions between the associations of parity, lactation length and weaning to conception interval with subsequent litter size in swine herds using early weaning. Preventative Veterinary Medicine 37: 113-120.

Kongsted, A.G. (2005). A review of the effect of energy intake on pregnancy rate and litter size discussed in relation to group-housed nonlactating sows. Livestock Production Science 97: 13-26.

Lawlor, P. (1998). Boar management. In: Proceedings of Teagasc Pig Farmers Conferences. Teagasc, Oakpark, Carlow. pp20-29.

Lawlor, P. (2005). Selecting gilts for increased sow longevity. In: Proceedings of Teagasc Pig Farmers Conferences. Teagasc, Oakpark, Carlow. pp39-44.

Lynch, P.B. (2001). Factors affecting voluntary feed intake in the sow during the lactation period. PhD Dissertation, National University of Ireland, Dublin, Ireland.

Noblet, J., Dourmad, J.Y. and Etienne, M. (1990). Energy utilisation in pregnant and lactating sows: modelling for energy requirements. Journal of Animal Science 68: 562-572.

NRC (1998). Nutrient Requirements of Swine. National Academic Press, Washington, DC, USA. p189.

O'Grady, J.F. and Lynch, P.B. (1978). Voluntary feed intake by lactating sows: influence of system of feeding and nutrient density of the diet. Irish Journal of Agricultural Research 17: 1-5.

O'Grady, J.F., Lynch, P.B. and Kearney, P.A. (1985). Voluntary feed intake by lactating sows. Livestock Production Science 12: 355-366.

Peng, J.J., Somes, S.A. and Rozeboom, D.W. (2006). Effect of system of feeding and watering on the performance of lactating sows. Journal of Animal Science 85: 853-860.

Peterson, B.A., Ellis, M., Wolter, B.F. and Williams, N. (2004). Effect of lactation feeding strategy on sow and gilt litter performance. Journal of Animal Science 82 (1): 148.

PIGSYS (2006). PIGSYS data analysis. Report 2005. Teagasc Pig Production Development Service, Athenry. p11.

Rodriguez-Zas, S.L., Davis, C.B., Ellinger, P.N., Schnitkey, G.D., Romine, N.M., Connor, J.F., Knox, R.V. and Southey, B.R. (2006). Impact of biological and economic variables on optimal parity for replacement in swine breed to wean herds. Journal of Animal Science 84: 2555-2565.

Rothschild, M.F. and Bidanel, J.P. (1998). Biology and genetics of reproduction. In: M.F. Rothschild and A. Ruvinsky (eds.) The Genetics of the Pig. Cambridge: CAB International, University Press. pp313-343. Simultaneously optimizing farrowing rate and litter size. (2000). Swine News 23 (7) [Online]. Available from: http://mark.asci.ncsu.edu/Swine_ News/2000/aug00.pdf

Spötter, A. and Distl, O. (2006). Genetic approaches to the improvement of fertility traits in the pig. The Veterinary Journal 172: 234-247.

Stalder, K.J., Knauer, M. Baas, T.J. Rothschild, M.F. and Mabry, J.W. (2004). Sow Longevity. Pig News and Information 25: 53N-74N. Stalder, K. and Bass, T. (2005a). Poster Series Introduced. National Hog Farmer [Online]. Available from: http://nationalhogfarmer.com/mag/ farming_poster_series_introduced/

Stalder, K. and Bass, T. (2005b). Screen Gilts for Feet and Leg Disorders. National Hog Farmer [Online]. Available from: http://nationalhogfarmer. $\mathrm{com} / \mathrm{mag} /$ farming_screen_gilts_feet/

Stalder, K. and Bass, T.(2005c). Reproductive Trait Selection Guidelines. National Hog Farmer [Online]. Available from: http://nationalhogfarmer. $\mathrm{com} / \mathrm{mag} /$ farming_reproductive_trait_selection/

Steverink, D.W.B., Soede, N.M., Bouwman, E.G. and Kemp B. (1998). Semen backflow after insemination and its effect on fertilisation results in sows. Animal Reproduction Science 54: 109-119.

Tantasuparuk, W., Dalin, A.M., Lundeheim, N., Kunavongkrit, A. and Einarsson, S. (2001). Body weight loss during lactation and its influence on weaning to service interval and ovulation rate in Landrace and Yorkshire sows in the tropical environment of Thailand. Animal Reproduction Science 65: 273-281.

Thaker, M.Y.C. and Bilkei, G. (2005). Lactation weight loss influences subsequent reproductive performance of sows. Animal Reproduction Science. 88: 309-318.

Tokach, M., Dritz, S., Goodband, B. and Nelssen, J. (1999). Nutrition for Optimal Performance of the female pig. In: Proceedings of Teagasc Pig Farmers Conferences, Teagasc, Sandymount Avenue, Dublin 4. pp96-110. Tummaruk, P., Lundeheim, N., Einarsson, S., Dalin, A.M. (2000). Reproductive performance of purebred Swedish Landrace and Swedish Yorkshire sows: 11. Effect of mating type, weaning to first service interval and lactation length. Acta Agriculturae Scandinavica 50: 217-224.

Tummaruk, P., Lundeheim, N., Einarsson, S. and Dalin, A.M. (2001). Effect of birth litter size, birth parity number, growth rate, backfat thickness and age at first mating of gilts on their reproductive performance as sows. Animal Reproduction Science 66: 225-237.

Wu, G., Bazer, F.W., Wallace, J.M. and Spencer, T.E. (2006). Board invited review: Intrauterine growth retardation: Implications for the animal sciences. Journal of Animal Science 84: 2316-2337.

Young, M. (2003). Nutrition and management of the modern gilt. In: Proceedings of Teagasc Pig Farmers Conferences, Teagasc, Sandymount Avenue, Dublin 4. pp41-54.

Zak. L.J., Cosgrove, J.R., Aherne, F.X. and Foxcroft, G.R. (1997).

Patterns of feed intake and associated metabolic and endocrine changes differentially affect postweaning fertility in primiparous sows. Journal of Animal Science 75: 208-216. 


\section{Appendix 1}

Table 1.1: Gestation feed curve for sows calculated from NRC (1998) equations and using the feeding pattern proposed by Tokach et al. $(1999)^{1}$

\begin{tabular}{|l|l|}
\hline Days after service & MJ DE / day ${ }^{2}$ \\
\hline $0-12$ & 24.2 \\
\hline $13-45^{3}$ & 30.4 \\
\hline $46-100$ & 25.1 \\
\hline $101-112$ & 38.1 \\
\hline $113-115$ & 25.1 \\
\hline Total Intake (MJ DE) & 3208 \\
\hline Mean Daily intake (MJ DE) & 28.0 \\
\hline Mean Daily intake (kg/day) & 2.15 \\
\hline
\end{tabular}

${ }^{1}$ For a sow of $180 \mathrm{~kg}$, gaining $10 \mathrm{~kg}$ in body weight (above the normal weight increase due to uterine growth, uterine fluids, products of conception and mammary tissue; assumed to be $22.8 \mathrm{~kg}$ ) during pregnancy and fed a diet containing $13 \mathrm{MJ} \mathrm{DE} / \mathrm{kg}$.

${ }^{2}$ Increase feed curve at each stage by $(0.92 \mathrm{MJ} \mathrm{DE}$ per day $)$ or approx. $3.5 \%$ for each $10 \mathrm{~kg}$ in sow weight above $180 \mathrm{~kg}$.

${ }^{3}$ Increase curve at day $13-45$ by $6.2 \mathrm{MJ} /$ day for each additional $10 \mathrm{~kg}$ in body weight gain required during gestation.

Table 1.2: Gestation feed curve for gilts calculated from NRC (1998) equations and using the feeding pattern proposed by Tokach et al. (1999) ${ }^{1}$.

\begin{tabular}{|l|l|}
\hline Days after service & MJ DE / day ${ }^{2}$ \\
\hline $0-12$ & 20.3 \\
\hline $13-45^{3}$ & 39.0 \\
\hline $46-100$ & 23.2 \\
\hline $101-112$ & 36.2 \\
\hline $113-115$ & 23.2 \\
\hline Total Intake (MJ DE) & 3313 \\
\hline Mean Daily intake (MJ DE) & 28.8 \\
\hline Mean Daily intake (kg/day) & 2.22 \\
\hline
\end{tabular}

${ }^{1}$ For a gilt of $140 \mathrm{~kg}$, gaining $30 \mathrm{~kg}$ in body weight (above the normal weight increase due to uterine growth, uterine fluids, products of conception and mammary tissue; assumed to be $22.8 \mathrm{~kg}$ ) during pregnancy and fed a diet containing $13 \mathrm{MJ} \mathrm{DE} / \mathrm{kg}$. ${ }^{2}$ Increase feed curve at each stage by ( $1 \mathrm{MJ}$ DE per day) or approx $4 \%$ for each $10 \mathrm{~kg}$ in sow weight above $140 \mathrm{~kg}$.

${ }^{3}$ Increase curve at day $13-45$ by $6.2 \mathrm{MJ} /$ day for each additional $10 \mathrm{~kg}$ in body weight gain required during gestation.

Note:

1. The above curves should not be used without consulting the footnotes. If unsure of any of the details an advisor or nutritionist should be consulted.

2. Sows that are extremely thin or that have lost excessive condition during lactation should always be fed to condition from the beginning of pregnancy.

3. An additional $1 \mathrm{MJ}$ DE per day should be fed where effective temperature drops below $18^{\circ} \mathrm{C}$.

4. Sows with mange or other parasites will require additional food.

5. Sows' condition should always be closely monitored during gestation. If expected weight gains are not achieved then adjustments in the curve may be necessary.

\section{Appendix 2}

Table 2.1: Lactation feed curves (MJ DE) used in sow feed studies at Teagasc, Moorepark

\begin{tabular}{|c|c|c|c|}
\hline Days & Curve 1 & Curve 2 & Curve 3 \\
\hline 0 & 25.0 & 28.8 & 33.1 \\
\hline 1 & 35.0 & 40.3 & 46.3 \\
\hline 2 & 38.3 & 44.1 & 50.7 \\
\hline 3 & 41.7 & 47.9 & 55.1 \\
\hline 4 & 45.0 & 51.8 & 59.5 \\
\hline 5 & 50.0 & 57.5 & 66.1 \\
\hline 6 & 55.0 & 63.3 & 72.7 \\
\hline 7 & 60.0 & 69.0 & 79.4 \\
\hline 8 & 65.0 & 74.8 & 86.0 \\
\hline 9 & 68.8 & 79.1 & 90.9 \\
\hline 10 & 72.5 & 83.4 & 95.9 \\
\hline 11 & 76.3 & 87.7 & 100.8 \\
\hline 12 & 80.0 & 92.0 & 105.8 \\
\hline 13 & 83.3 & 95.8 & 110.2 \\
\hline 14 & 86.7 & 99.7 & 114.6 \\
\hline 15 & 90.0 & 103.5 & 119.0 \\
\hline 16 & 91.7 & 105.4 & 121.2 \\
\hline 17 & 93.3 & 107.3 & 123.4 \\
\hline 18 & 95.0 & 109.3 & 125.6 \\
\hline 19 & 95.6 & 109.9 & 126.4 \\
\hline 20 & 96.2 & 110.6 & 127.2 \\
\hline 21 & 96.8 & 111.3 & 128.0 \\
\hline 22 & 97.4 & 112.0 & 128.8 \\
\hline 23 & 98.0 & 112.7 & 129.6 \\
\hline 24 & 98.0 & 112.7 & 129.6 \\
\hline 25 & 98.0 & 112.7 & 129.6 \\
\hline 26 & 98.0 & 112.7 & 129.6 \\
\hline 27 & 98.0 & 112.7 & 129.6 \\
\hline 28 & 98.0 & 112.7 & 129.6 \\
\hline \multicolumn{4}{|l|}{26 days $^{1}$} \\
\hline $\begin{array}{l}\text { Total feed } \\
\text { (MJ DE) }\end{array}$ & 1932.5 & 2222.4 & 2555.7 \\
\hline $\begin{array}{l}\text { Mean daily feed } \\
\text { (MJ DE) }\end{array}$ & 74.3 & 85.5 & 98.3 \\
\hline Total feed (kg) & 136.1 & 156.5 & 180.0 \\
\hline $\begin{array}{l}\text { Mean daily feed } \\
\text { (kg) }\end{array}$ & 5.2 & 6.0 & 6.9 \\
\hline
\end{tabular}

${ }^{1}$ Feed intake is calculated for a 26-day lactation which is the mean lactation on Irish herds. 